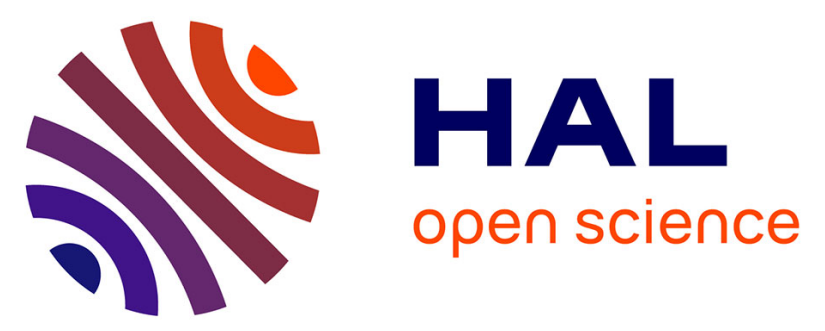

\title{
Glutamate optimizes enzymatic activity under high hydrostatic pressure in Desulfovibrio species: effects on the ubiquitous thioredoxin system
}

\author{
Hélène Gaussier, M. Nouailler, Edouard Champaud, Edwige Garcin, Sebban
}

-Kreuzer, Olivier Bornet, Marc Garel, Christian Tamburini, Laetitia Pieulle, Alain Dolla, et al.

\section{To cite this version:}

Hélène Gaussier, M. Nouailler, Edouard Champaud, Edwige Garcin, Sebban -Kreuzer, et al.. Glutamate optimizes enzymatic activity under high hydrostatic pressure in Desulfovibrio species: effects on the ubiquitous thioredoxin system. Extremophiles, 2021, 25, pp.385-392. 10.1007/s00792-021-01236x . hal-03272295

\section{HAL Id: hal-03272295 \\ https://hal.science/hal-03272295}

Submitted on 28 Jun 2021

HAL is a multi-disciplinary open access archive for the deposit and dissemination of scientific research documents, whether they are published or not. The documents may come from teaching and research institutions in France or abroad, or from public or private research centers.
L'archive ouverte pluridisciplinaire HAL, est destinée au dépôt et à la diffusion de documents scientifiques de niveau recherche, publiés ou non, émanant des établissements d'enseignement et de recherche français ou étrangers, des laboratoires publics ou privés. 
Glutamate optimizes enzymatic activity under high hydrostatic pressure in Desulfovibrio species: effects on the ubiquitous thioredoxin system

Gaussier $\mathrm{H}^{1 \#}$, Nouailler $\mathrm{M}^{2 \#}$, Champaud $\mathrm{E}^{1}$, Garcin E. $\mathrm{B}^{2}$, Sebban-Kreuzer $\mathrm{C}^{2}$, Bornet, $\mathrm{O}^{3}$, Garel $\mathrm{M}^{1}$, Tamburini $\mathrm{C}^{1}$, Pieulle $\mathrm{L}^{4}$, Dolla $\mathrm{A}^{1 *}$ and Pradel $\mathrm{N}^{1 *}$

1. Aix Marseille Univ, Université de Toulon, CNRS, IRD, MIO, Marseille, France

2. Aix Marseille Univ, CNRS, LISM, Marseille, France

3. Aix Marseille Univ, CNRS, IMM, Marseille, France

4. Aix Marseille Univ, CNRS, LCB, Marseille, France

\# both authors contribute equally to this work

* To whom correspondence should be sent:

Alain Dolla : Email: alain.dolla@mio.osupytheas.fr

Nathalie Pradel; Email: nathalie.pradel@ird.fr

\section{ABSTRACT}

In piezophilic microorganisms, enzymes are optimized to perform under high hydrostatic pressure. The two major reported mechanisms responsible for such adaptation in bacterial species are changes in amino acids in the protein structure, favoring their activity and stability under high-pressure conditions, and the possible accumulation of micromolecular co-solutes in the cytoplasm. Recently, the accumulation of glutamate in the cytoplasm of piezophilic Desulfovibrio species has been reported under high pressure growth conditions. In this study, analysis of the effect of glutamate on the enzymatic activity of the thioredoxin reductase/thioredoxin enzymatic complex of either a piezosensitive or a piezophilic microorganism confirms its role as a protective co-solute. Analysis of the thioredoxin structures suggests an adaptation both to the presence of glutamate and to high hydrostatic pressure in the enzyme from the piezophilic strain. Indeed, the presence of large surface pockets could counterbalance the overall compression that occurs at high hydrostatic pressure to maintain enzymatic activity. A lower isoelectric point and a greater dipolar moment than that of thioredoxin from the piezosensitive strain would allow the protein from the piezophilic strain to compensate for the presence of the charged amino acid glutamate to interact with its partner.

KEYWORDS: hydrostatic pressure, co-solute, glutamate, thioredoxin. 


\section{INTRODUCTION}

High hydrostatic pressure impacts all cellular components of microorganisms and modifies the activity of numerous key processes, such as enzymatic activities, eventually leading to the cell death of piezosensitive organisms (Abe 2007). As a general rule, secondary and tertiary structures of proteins remain stable at hydrostatic pressures below $500 \mathrm{MPa}$ (Robinson and Sligar 1995). Within the physiologically relevant pressure range, the most important pressure effect is on the solvation of the core protein, which is enhanced with increasing hydrostatic pressure, leading to protein inactivation (Robinson and Sligar 1994; Robinson and Sligar 1995). Hydrostatic pressure may also induce proteinprotein complex dissociation by weakening electrostatic and hydrophobic contacts which stabilize the complex (Gross and Jaenicke 1994). However, enzymes of high-pressure-adapted bacteria have been found to be more functional under high-pressure conditions than at atmospheric pressure (Le Bihan et al. 2013). Only a few enzymatic activities of piezophilic microorganisms have been studied. Regarding the 3-isopropylmalate dehydrogenase of Shewanella bentica, pressure adaptation has been attributed to a single amino acid substitution affecting the activity of the enzyme by modifying water molecule penetration into the active site, thus decreasing the hydration structure of the enzyme at high hydrostatic pressure (Hamajima et al. 2016). Dynamic simulations of the dihydrofolate reductase of Moritella profunda have indicated that atomic fluctuations of the loops, which are important for enzyme function, were increased with pressure by weakening hydrogen bonds (Huang et al. 2019). These intrinsic molecular adaptations have led to proteins that are more resistant to high hydrostatic pressure than their shallow-water counterparts (Yancey and Siebenaller 2015).

Another important finding in piezophilic organisms is the cellular accumulation of micromolecular osmolyte-type co-solutes, called "piezolytes" (Martin et al. 2002), that counteract the pressure effect, corresponding to extrinsic adaptation (Yancey and Siebenaller 2015). For example, trimethylamine Noxide (TMAO), a well-known osmolyte suspected to interact indirectly with the protein through the surrounding water (Fedotova et al. 2017), has been reported in marine eukaryotes (Yancey et al. 2015). $\beta$-Hydroxybutyrate has been shown to accumulate at 20-30 MPa in P. profundum (Martin et al. 2002), and similarly, the intracellular concentration of ectoine has been shown to increase with pressure in Alcanivorax borkumensis (Scoma et al. 2016).

The role of piezolytes is to aid in maintaining protein function as well as macromolecule interactions within the cell at high hydrostatic pressure. The mechanism of action of these molecules is still largely unknown, but one can imagine that they act on protein solvation by helping to resist pressure-driven water penetration in the protein/complex core (Sarma and Paul 2013). It has been proposed that stabilization of proteins by ectoine is linked to its high hydration and exclusion from the water-protein interface. According to the Le Chatelier principle, this should tend toward a minimization of the area 
of the water-protein interface obtained when the protein is in its native state and thus stabilizes the native structure through the "preferential exclusion model" (Arakawa and Timasheff 1985; Eiberweiser et al. 2015). Among the co-solutes of interest, glutamate has been shown to intracellularly accumulate in piezophilic Desulfovibrio species, D. piezophilus and D. hydrothermalis, under high hydrostatic pressure up to $100 \mathrm{mM}$ and $200 \mathrm{mM}$ at $26 \mathrm{MPa}$ for D. piezophilus and D. hydrothermalis, respectively (Amrani et al. 2014; Amrani et al. 2016). On the other hand, neither the biosynthesis pathways of ectoine nor that of TMAO are present in the genomes of these strains. Glutamate has also notably been shown to be important for osmoregulation and survival during osmotic stress in several bacterial species (Saum and Müller 2007; Kang and Hwang 2018).

To better understand the effects of glutamate in the cell, we analyzed the structure of the model enzyme thioredoxin and the effect of glutamate on its activity at high hydrostatic pressure. Thioredoxins are small thiol:disulfide oxidoreductases ( $12 \mathrm{kDa})$ ubiquitous in all domains of life that play a central role in the control of the thiol/disulfide redox balance of the cytoplasm as part of the NADPH-dependent thioredoxin reductase (TR)/thioredoxin (Trx) system. They have a highly conserved fold consisting of a central $\beta$-sheet surrounded by four $\alpha$-helices and an active site with two cysteine residues that specify the biological activity of the protein (Martin 1995). Our study specifies the effect of glutamate on the enzymatic activity of TR/Trx complexes from the piezophile Desulfovibrio piezophilus C1TLV30 and the piezosensitive Desulfovibrio vulgaris Hildenborough sulfate reducers (Pieulle et al. 2011). This study shows that the structure of the TR/Trx system from piezophilic species is adapted to the presence of glutamate. Factors of this adaptation are discussed in light of the NMR structure of the $D$. vulgaris thioredoxin solved for this study and the structural modeling of the $D$. piezophilus thioredoxin.

\section{MATERIALS AND METHODS}

Cloning of $\boldsymbol{D}$. piezophilus C1TLV30 TR/Trx system. BN4v2_10319 (trx1) and BN4v2_10320 (trB) coding

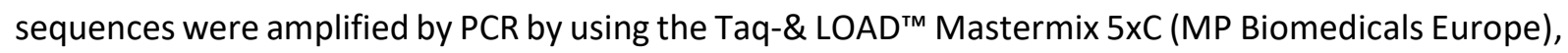
with D. piezophilus C1TLV30 genomic DNA (GenBank accession $n^{\circ} \mathrm{FO} 203427$ ) as the template, using primers pairs trx1-10319-fwHis and trx1-10319-rev, and trB-10320-fwHis and $\operatorname{trB}-10320-r e v$, respectively. Forward and reverse oligonucleotide primer sequences are listed in Table 1. A cloning procedure was designed to introduce one $\mathrm{N}$-terminal His-tag as already published (Pieulle et al. 2011). The resulting amplicon was purified using the Wizard SV Gel and PCR Clean-Up System from Promega and digested with the appropriate restriction enzymes purchased from New England Biolabs (Table 1). The trx1 and trB amplicons were cloned into pJF119EH and the vector was screened by PCR using 
primers p119+ and p119-, as previously described (Pieulle et al. 2011), to generate plasmids p319 and p320, respectively.

Protein production and purification. E. coli TG1 was used for heterologous expression of both TR- and Trx-encoding genes as previously described (Pieulle et al. 2011). Recombinant E. coli TG1 strains were grown in either Luria-Bertani (LB), 2YT, or M9-glucose medium (Sambrook et al. 1989) with ampicillin (100 $\mu \mathrm{g} / \mathrm{mL})$. For D. piezophilus C1TLV30 Trx1 (DpTrx1) production, E. coli TG1 (p139) was grown overnight in LB medium at $37^{\circ} \mathrm{C}$; this culture was used to inoculate 1 liter of $2 \mathrm{YT}$ medium ( $\left.1 \% \mathrm{vol} / \mathrm{vol}\right)$. The culture was incubated at $37{ }^{\circ} \mathrm{C}$ until the optical density at $600 \mathrm{~nm}\left(\mathrm{OD}_{600 \mathrm{~nm}}\right)$ reached 0.6. DpTrx1 production was then induced by adding a final concentration of $0.5 \mathrm{mM}$ isopropyl $\beta$-D-1thiogalactopyranoside (IPTG). Cells were further grown for $4 \mathrm{~h}$ and harvested by centrifugation (20 min at $7,000 \times \mathrm{g}, 4{ }^{\circ} \mathrm{C}$ ), and the pellet was stored at $-80^{\circ} \mathrm{C}$. For D. piezophilus C1TLV30 TR (DpTR1) production, E. coli TG1 (p320) was grown overnight in LB medium at $37^{\circ} \mathrm{C}$; this culture was further used to inoculate 1 liter of M9-glucose medium ( $1 \%$ vol/vol). Cells were grown at $37^{\circ} \mathrm{C}$ until the $\mathrm{OD}_{600 \mathrm{~nm}}$ reached 0.8. TR production was then induced by adding a final concentration of $1 \mathrm{mM} \mathrm{IPTG}$, and the cells were further grown for $16 \mathrm{~h}$ and then harvested by centrifugation $\left(20 \mathrm{~min}\right.$ at $7,000 \times \mathrm{g}, 4^{\circ} \mathrm{C}$ ). The pellet was stored at $-80^{\circ} \mathrm{C}$. His-tagged DpTrx1 and DpTR1 were purified as previously described for DvTrx1 and DpTR1 (Pieulle et al. 2011). Production and purification of recombinant Trx1 (DvTrx1) and TR1 (DvTR1) from D. vulgaris Hildenborough was performed as previously described (Pieulle et al. 2011). The purity of the proteins was checked by SDS-PAGE on a $12.5 \%$ polyacrylamide gel using the Instant Blue (Coomassie Blue) staining procedure (Expedon, UK). Trx1 concentrations were measured using the Pierce BCA Protein Assay Kit (Thermo Scientific), and TR1 concentrations were calculated using the $\varepsilon_{451 \mathrm{~nm}}$ value of $11,300 \mathrm{M}^{-1} . \mathrm{cm}^{-1}$.

Steady state kinetics analysis for optimization of the experiments at $0.1 \mathrm{MPa}$. The reaction mixture was composed of $0.1 \mathrm{M}$ potassium phosphate buffer, $\mathrm{pH}$ 7.5, $2 \mathrm{mM}$ EDTA, $1 \mathrm{mM}$ DTNB, and $1 \mathrm{mM}$ NADPH complemented with different volumes of sodium glutamate solution to reach a final concentration of $0,10,50,100$ or $500 \mathrm{mM}$ glutamate for a final reaction volume of $200 \mu \mathrm{L}$. A final concentration of $10 \mu \mathrm{M}$ Trx1 and $0.1 \mu \mathrm{M}$ TR1 reductase from either $D$. piezophilus or $D$. vulgaris was added to initiate the reaction. As controls, water replaced the enzyme and/or glutamate. Kinetic experiments were recorded by measuring the optical density at $412 \mathrm{~nm}\left(\mathrm{OD}_{412 \mathrm{~nm}}\right)$ with a Shimadzu UV1601 spectrophotometer under constant stirring. The DTNB reduction spectroscopic signal was converted into $\mu \mathrm{M}$ concentration by using the Beer-Lambert law $\left(\varepsilon^{\mathrm{DTNB}}{ }_{412 \mathrm{~nm}}=14,150 \mathrm{M}^{-1} \cdot \mathrm{cm}^{-1}\right)$. Each experiment was performed in triplicate. 
140 Enzymatic activity assays at 0.1 and $25 \mathrm{MPa}$. Reactions ( $200 \mu \mathrm{L}$ final volume) were performed in $2 \mathrm{~mL}$ borosilicate glass syringes (Socorex Dosys, Swiss). For the experiments at $25 \mathrm{MPa}$, syringes were inserted into $250 \mathrm{~mL}$-volume high-pressure bottles (HPBs), and the hydrostatic pressure was controlled using a manual manometer. A reaction mixture of $0.1 \mathrm{M}$ potassium phosphate buffer, $\mathrm{pH} 7.5,2 \mathrm{mM}$ EDTA, $1 \mathrm{mM}$ DTNB, and $1 \mathrm{mM}$ NADPH was prepared with or without $100 \mathrm{mM}$ glutamate. Each reaction mixture was separated into four $200 \mu \mathrm{L}$ samples. For each pressure condition ( 0.1 and $25 \mathrm{MPa}$ ), one sample was prepared by adding $10 \mu \mathrm{M}$ Trx 1 and $0.1 \mu \mathrm{M}$ TR1, and a control was prepared by replacing the enzymes with $\mathrm{H}_{2} \mathrm{O}$. All buffers, enzyme stocks and reactive were kept on ice. Incubations were performed at 0.1 or $25 \mathrm{MPa}$ at $25^{\circ} \mathrm{C}$ for $45 \mathrm{~min}$. Then, the HPBs were quickly depressurized, and the $\mathrm{OD}_{412 \mathrm{~nm}}$ of each reaction mixture was measured. $\mathrm{OD}_{412 \mathrm{~nm}}$ of blank reactions were subtracted from the reaction sample $\mathrm{OD}_{412 \mathrm{~nm}}$, and the Beer-Lambert law was applied to calculate the molar quantity of DTNB hydrolyzed in $45 \mathrm{~min}\left(\varepsilon^{\mathrm{DTNB}}{ }_{412 \mathrm{~nm}}=14,150 \mathrm{M}^{-1} \cdot \mathrm{cm}^{-1}\right)$. Each experiment was performed in triplicate.

DvTrx1 structure calculation. The NMR sample contained $1 \mathrm{mM}$ DvTrx1 $\left(10 \% \mathrm{D}_{2} \mathrm{O}, 90 \% \mathrm{H}_{2} \mathrm{O}\right)$ in 50 $\mathrm{mM}$ phosphate buffer and $100 \mathrm{mM} \mathrm{NaCl}, \mathrm{pH}$ 5.5. The spectra were analyzed with CARA (Keller 2004) based on the resonance assignment previously deposited at the BMRB under accession code 17299. For structure calculations, 84 restraints were used for backbone hydrogen bonds, 170 backbone $\varphi$ and $\psi$ dihedral restraints derived from TALOS (Cornilescu et al. 1999) and 2071 nOe (nuclear Overhauser effect). The 20 lowest energy structures were water refined using the Amber 4.1 force field. The structural coordinates have been deposited in the Protein Data Bank under accession number 6ZOM.

DpTrx1 structural model. A homology model of oxidized DpTrx1 was generated with the Swiss-Model server (Waterhouse et al. 2018) based on the template structure of the oxidized thioredoxin DvTrx1 (pdb 6ZOM). The internal cavities and the ribbon models were generated with PyMOL (PyMOL Molecular Graphics System, Version 2.0 Schrödinger, LLC). Volume cavities were measured with the CastP server, with a radius probe of $0.9 \AA$ (Tian et al. 2018) and with Void protein (Cuff and Martin 2004). Electrostatic potentials were calculated with the APBS module of PyMOL.

Data Analysis. Statistical analyses were performed with XLSTAT (Addinsoft) using the Student's t-test. Values were considered different at the $\alpha=0.01$ significance level. 
Sequence properties of the $D$. piezophilus thioredoxin system. $D$. piezophilus $\operatorname{Trx} 1$, encoded by the trx1 gene (BN4v2_10319), contained the classical WCGPC active site motif; in addition, the two residues Asp-24 and Lys-55, found in Trx1 of the piezosensitive $D$. vulgaris Hildenborough strain, that have been suggested to deprotonate Cys-32 and to contribute to proton uptake accompanying the reduction of Trx1 (Pieulle et al. 2011), were conserved in DpTrx1 (Fig. 1a). Amino acid sequence alignment of DpTrx1 and DvTrx1 showed 84 identical residues (78.50\%), 10 strongly similar residues (9.35\%), 5 weakly similar residues (4.67\%) and 8 different residues (7.48\%) (Fig. 1a). The thioredoxin reductase of $D$. piezophilus C1TLV30, encoded by the $\operatorname{trB}$ gene (BN4v2_10320), exhibited the signature motifs vxxxHRRDxxRA and GGGxxAxE required for NADPH binding and the GR/KG and FF motifs for the thioredoxin binding site and the $\mathrm{CxxC}$ active site (Fig. 1b). These sequence elements show that the thioredoxin reductase of $D$. piezophilus C1TLV30 belongs to the TR1 group, as defined by Valette and coworkers (Valette et al. 2017). Overall, these findings show that the D. piezophilus C1TLV30 genome encodes one classical TR/Trx system homologous to the $D$. vulgaris Hildenborough TR1/Trx1 system.

Comparative enzymatic activities of the thioredoxin systems: DTNB reduction by the TR1/Trx1 complexes from D. piezophilus C1TLV30 and D. vulgaris Hildenborough was studied at both atmospheric pressure $(0.1 \mathrm{MPa})$ and high hydrostatic pressure (25 MPa), with or without $100 \mathrm{mM}$ glutamate (Fig. 2). Experiments were based on final DTNB reduction over a $45 \mathrm{~min}$ time period. In the absence of glutamate, the amounts of DTNB reduced by the $D$. piezophilus TR1/Trx1 complex were higher at $25 \mathrm{MPa}(29.4 \pm 6.4 \mu \mathrm{M})$ than at $0.1 \mathrm{MPa}(5.8 \pm 2.4 \mu \mathrm{M})(\mathrm{p}$-value<0.01) (Fig. 2a). The activity of the D. vulgaris TR1/Trx1 complex was higher at atmospheric pressure than at $25 \mathrm{MPa}(36.4 \pm 4.5$ $\mu \mathrm{M}$ versus $15.1 \pm 4.6 \mu \mathrm{M}$ of reduced DTNB, respectively ( $p$-value $<0.01)$ ) (Fig. $2 b)$. Thus, both complexes showed the highest activity under the hydrostatic pressure that the cells usually encounter, i.e., high hydrostatic pressure for $D$. piezophilus and atmospheric pressure for $D$. vulgaris. When the complexes were placed under unfavorable hydrostatic pressure for the corresponding cells, their activity was lower, as the $D$. piezophilus TR1/Trx1 complex lost $85 \%$ of its activity at $0.1 \mathrm{MPa}$, and the $D$. vulgaris TR1/Trx1 complex lost $58 \%$ of its activity at $25 \mathrm{MPa}$. This shows that the D. piezophilus TR1/Trx1 complex is adapted to high hydrostatic pressure conditions, in agreement with the piezophilic nature of $D$. piezophilus C1TLV30, while the $D$. vulgaris TR1/Trx1 complex is better adapted to atmospheric pressure, in agreement with the piezosensitive nature of $D$. vulgaris Hildenborough.

To assess the effect of glutamate as pressure co-solute, the activities of both TR1/Trx1 complexes were measured in the presence of glutamate. To first evaluate the diffusion effect of the substrate toward the enzymes, the initial velocity under steady-state conditions for DTNB reduction by the $D$. vulgaris TR1/Trx1 complex was measured at different glutamate concentrations under constant stirring (Fig. 3). No significant change in the initial velocity was recorded from 0 to $100 \mathrm{mM}$ glutamate ( $\mathrm{p}$ - 
value $>0.01$ ), meaning that the increase in density due to glutamate could be easily compensated by gentle mechanical stirring. When the glutamate concentration increased to $500 \mathrm{mM}$, the velocity decreased from approximately $8 \mu \mathrm{M} \cdot \mathrm{min}^{-1}$ to $6 \mu \mathrm{M} \cdot \mathrm{min}^{-1}$. It should be noted that the $\mathrm{pH}(\sim 7.5)$ was not modified by the addition of glutamate until $100 \mathrm{mM}$ and slightly increased to 7.8 in the presence of $500 \mathrm{mM}$ glutamate. The decrease of approximately $20 \%$ in the velocity in the presence of $500 \mathrm{mM}$ glutamate may thus be related to a decrease in the capacity of the substrate to diffuse through this viscous environment, despite constant stirring. Since intracellular glutamate accumulation was estimated at approximately $100 \mathrm{mM}$ in D. piezophilus cells grown at $26 \mathrm{MPa}$ (Amrani et al. 2014) and since our results showed a very close kinetic behavior from 0 to $100 \mathrm{mM}$ glutamate and therefore no inhibitory effect, this latter concentration was kept for further experiments.

In the presence of $100 \mathrm{mM}$ glutamate, the amount of DTNB reduced by the $D$. piezophilus TR1/Trx1 complex increased significantly at $0.1 \mathrm{MPa}$, from $4.4 \pm 2.4 \mu \mathrm{M}$ without glutamate to $21.6 \pm 6.5 \mu \mathrm{M}$ with glutamate ( $p$-value<0.01) (Fig. 2a). In contrast, no significant difference in the activity of the $D$. vulgaris TR1/Trx1 complex at 0.1 MPa was observed with or without glutamate (Fig. 2b). At $25 \mathrm{MPa}$, an upward trend in the activity of the $D$. piezophilus TR1/Trx1 complex in the presence of glutamate was noticed (37.1 $\pm 6.9 \mu \mathrm{M}$ versus $29.4 \pm 6.4 \mu \mathrm{M}$ of reduced DTNB with and without glutamate, respectively) (Fig. 2a). Similarly, an increase in the amount of DTNB reduced by the $D$. vulgaris TR1/Trx1 complex was observed in the presence of $100 \mathrm{mM}$ glutamate $(43.7 \mu \mathrm{M}$ versus $15.1 \mu \mathrm{M}$ without glutamate (mean values)) (Fig. 2b). However, the standard deviations observed for the experiments performed with the D. piezophilus TR1/Trx1 complex in the presence of glutamate at both 0.1 and $25 \mathrm{MPa}$ were much lower than those obtained with the $D$. vulgaris TR1/Trx1 complex. It should be noted that these experiments were performed using a single point activity measurement after $45 \mathrm{~min}$ of incubation without stirring and thus were highly dependent on the turnover of the enzymes. Because the largest standard deviations were observed for the Dv TR1/Trx1 complex in the presence of glutamate, it suggests that this latter affects especially the turnover of this enzymatic system. To understand this effect, the structures of the Trx1 from both species were determined.

\section{Structures of DvTrx1 and DpTrx1.}

To obtain more insights into the structural adaptation of the $D$. piezophilus TR1/Trx1 complex to high hydrostatic pressure and to the presence of glutamate, comparison of the three-dimensional structure of the thioredoxins from D. vulgaris Hildenborough and D. piezophilus C1TLV30 was performed. First, the three-dimensional structure of DvTrx1 in the oxidized state was determined. The resulting ensemble of solutions, consisting of the 20 lowest energy structures of DvTrx1, adopted a typical thioredoxin fold: a five-stranded twisted central $\beta$-sheet surrounded by four $\alpha$-helices, with $\alpha 2$ and $\alpha 4$ helices on one side and $\alpha 1$ and $\alpha 3$ helices on the opposite side (Fig. 4a). The N-terminal motif 
$\beta 1 \alpha 1 \beta 2 \alpha 2 \beta 3$ was connected by the loop comprising the $\alpha 3$ helix to the $C$-terminal motif $\beta 4 \beta 5 \alpha 4$. The active site (CGPC) was formed by a protruding loop between strand $\beta 2$ and the $\mathrm{N}$-terminus of helix $\alpha 2$. The proline of the catalytic site generated a distortion in the $\alpha 2$ helix, separating the CGPC consensus from the rest of the helix. The electrostatic surface of DvTrx1 exhibited a charge repartition similar to that of canonical thioredoxins. Overall, the protein displayed high three-dimensional similarities to known thioredoxins such as E. coli Trx1 (Katti et al. 1990).

The homology model of DpTrx1, performed with the Swiss model, indicated a global model quality estimation (GMQE) of $0.66 / 1.00$, resulting in good reliability of the model (Fig. 4b). Only $0.4 \AA$ rmsd was evidenced between both thioredoxin three-dimensional structures, resulting in a typical thioredoxin fold of DpTrx1. Interestingly, the less conserved part of the protein was localized at the opposite side of the active site, in the $\alpha 1$ helix, which contained 2 additional glutamic acid residues at positions 13 and 18 that were replaced by serine and alanine, respectively, in DvTrx1. Two additional acidic residues were also found in DpTrx1: a glutamic acid at position 45 in the $\alpha 2$ helix, replaced by alanine in DvTrx1, and an aspartic acid at position 81, replaced by asparagine in DvTrx1 (Fig. 4a-d) (Fig. 1a). These structural features confer a more acidic calculated isoelectric point ( $p l=5.0$ for DpTrx1 versus 4.6 for DvTrx1) and a different dipolar moment, $21.4^{\circ}$ angle deviation and +104 Debyes for DpTrx1 (Fig. 4e). In addition, DpTrx1 had larger surface pockets than DvTrx1 (2003.5 $\AA^{3}$ versus 1878.5 $\AA^{3}$, respectively). Overall, the structure of DpTrx1 was $2 \%$ larger than that of DvTrx1. This structural comparison revealed two way of adaptation of DpTrx1. First, the surface pockets, which are larger than those in DvTrx1, could be compressed to compensate for the lack of flexibility under high pressure in the region of the cysteines. Second, the larger number of acidic residues in DpTrx1 compared to DvTrx1 could be linked to the adaptation of the protein sequence to the presence of glutamate in the cytoplasm of the cell; the resulting dipolar moment of the protein would counterbalance its presence by conferring an optimal orientation of Trx1 for TR1/Trx1 complex formation. It can be postulated that glutamate protects the protein core from pressure-driven water penetration and thus stabilizes the native conformation of the protein through either the "preferential exclusion model" (Arakawa and Timasheff 1985) or the "water replacement theory" (Crowe et al. 1990), which proposes that the molecule binds directly to the protein by replacing water molecules in the hydration shell of the protein. The activity of the TR1/Trx1 complex of $D$. piezophilus was greater at atmospheric pressure in the presence of glutamate than without glutamate, supporting the concept that the enzymes have adapted to the hydrostatic pressure and thus to the presence of glutamate, as glutamate accumulates at high hydrostatic pressure (Amrani et al. 2014). Structure of D. piezophilus Trx1 highlights peculiar features like a larger structure and surface pockets than its homologous protein 
278 isolated from the piezosensitive Desulfovibrio vulgaris strain. This could counterbalance the overall

279 compression that occurs at high hydrostatic pressure to maintain enzymatic activity. Additionally, $D$.

280 piezophilus Trx1 exhibits a relatively lower isoelectric point and a more pronounced dipolar moment

281 than those of DvTrx1, which could allow for the protein to compensate for the presence of intracellular

282 glutamate to interact with its partner. Altogether, the enzymatic data and the structural analysis of

283 Trx1 allow us to conclude that the Dp TR1/Trx1 system may be adapted to the presence of glutamate,

284 as opposite to the Dv TR1/Trx1 system. On a physiological point of view, antioxidant defense

285 mechanism has been shown to be an important mechanism to cope with high hydrostatic pressure in

286 the deep-sea bacterium Shewanella piezotolerans WP3 (Xie et al. 2018). In the same way, the TR1/Trx1

287 complex plays a key role in maintaining the redox homeostasis in the cell (Pieulle et al. 2011).

288 Adaptation of the $D$. piezophilus TR1/trx1 to the presence of glutamate is thus an advantage to

289 maintain antioxidant defense mechanism active under high hydrostatic pressure.

290 Overall, these data pointed out the protective role of glutamate in maintaining the enzymatic activity

291 of the TR1/Trx1 complex. Thus, adaptation to high hydrostatic pressure appears to be a complex

292 mechanism involving glutamate overproduction to protect the cell and the enzyme from pressure, and

293 structural changes to adapt to both hydrostatic pressure and the presence of glutamate.

294

295 Aknowledgement : This is a post-peer-review, pre-copyedit version of an article published in

296 Extremophiles. The final authenticated version is available online at:

297 https://dx.doi.org/10.1007/s00792-021-01236-x. 


\section{REFERENCES}

301

302

303

304

305

306

307

308

309

310

311

312

313

314

315

Abe $F$ (2007) Exploration of the effects of high hydrostatic pressure on microbial growth, physiology and survival: perspectives from piezophysiology. Biosci Biotechnol Biochem 71:2347-2357 doi: 10.1271/bbb.70015

Amrani A, Bergon A, Holota H, Tamburini C, Garel M, Ollivier B, Imbert J, Dolla A, Pradel N (2014) Transcriptomics reveal several gene expression patterns in the piezophile Desulfovibrio hydrothermalis in response to hydrostatic pressure. PLoS One 9:e106831 doi: 10.1371/journal.pone.0106831

Amrani A, van Helden J, Bergon A, Aouane A, Ben Hania W, Tamburini C, Loriod B, Imbert J, Ollivier B, Pradel N, Dolla A (2016) Deciphering the adaptation strategies of Desulfovibrio piezophilus to hydrostatic pressure through metabolic and transcriptional analyses. Environ Microbiol Rep 8:520-526 doi: 10.1111/1758-2229.12427

Arakawa T, Timasheff SN (1985) The stabilization of proteins by osmolytes. Biophys J 47:411-414 doi: 10.1016/S0006-3495(85)83932-1

Cornilescu G, Delaglio F, Bax A (1999) Protein backbone angle restraints from searching a database for chemical shift and sequence homology. J Biomol NMR 13: 289-302 doi: 10.1023/a:1008392405740

Crowe JH, Carpenter JF, Crowe LM, Anchordoguy TJ (1990) Are freezing and dehydration similar stress vectors? A comparison of modes of interaction of stabilizing solutes with biomolecules. Cryobiology 27:219-231 doi: 10.1016/0011-2240(90)90023-w

Cuff AL, Martin AC (2004) Analysis of void volumes in proteins and application to stability of the p53 tumour suppressor protein. J Mol Biol 344: 1199-1209 doi: 10.1016/j.jmb.2004.10.015

Eiberweiser A, Nazet A, Kruchinin SE, Fedotova MV, Buchner R (2015) Hydration and ion binding of the osmolyte ectoine. J Phys Chem B 119:15203-15211 doi: 10.1021/acs.jpcb.5b09276

Fedotova M, Kruchinin S, Chuev G (2017) Hydration structure of osmolyte TMAO: concentration/pressure-induced response. New J Chem 41:1219-1228 doi: 10.1039/C6NJ03296F

Gross M, Jaenicke R (1994) Proteins under pressure. The influence of high hydrostatic pressure on structure, function and assembly of proteins and protein complexes. Eur J Biochem 221:617630 doi: 10.1111/j.1432-1033.1994.tb18774.x

Hamajima Y, Nagae T, Watanabe N, Ohmae E, Kato-Yamada Y, Kato C (2016) Pressure adaptation of 3isopropylmalate dehydrogenase from an extremely piezophilic bacterium is attributed to a single amino acid substitution. Extremophiles 20:177-186 doi: 10.1007/s00792-016-0811-4

Huang Q, Rodgers J, Hemley R, Ichiye T (2019) Effects of pressure and temperature on the atomic fluctuations of dihydrofolate reductase from a psychropiezophile and a mesophile. IJMS 20:1452-1465 doi: 10.3390/ijms20061452

Kang Y, Hwang I (2018) Glutamate uptake is important for osmoregulation and survival in the rice pathogen Burkholderia glumae. PLoS One 13:e0190431 doi: 10.1371/journal.pone.0190431

Katti SK, LeMaster DM, Eklund H (1990) Crystal structure of thioredoxin from Escherichia coli at $1.68 \mathrm{~A}$ resolution. J Mol Biol 212:167-184 doi: 10.1016/0022-2836(90)90313-B

Keller RL (2004) The computer aided resonance assignment tutorial. Cantina Verlag, Goldau, Switzerland

Le Bihan T, Rayner J, Roy MM, Spagnolo L (2013) Photobacterium profundum under pressure: a MSbased label-free quantitative proteomics study. PLoS One 8:e60897 doi: 10.1371/journal.pone.0060897

Martin D, Bartlett D, Roberts M (2002) Solute accumulation in the deep-sea bacterium Photobacterium profundum. Extremophiles 6:507-514 doi: 10.1007/s00792-002-0288-1

Martin J (1995) Thioredoxin--a fold for all reasons. Structure 3:245-250 doi: 10.1016/s09692126(01)00154-x 
Pieulle L Stocker P, Vinay M, Nouailler M, Vita N, Brasseur G, Garcin E, Sebban-Kreuzer C, Dolla A (2011) Study of the thiol/disulfide redox systems of the anaerobe Desulfovibrio vulgaris points out pyruvate:ferredoxin oxidoreductase as a new target for thioredoxin 1. J Biol Chem 286:78127821 doi: 10.1074/jbc.M110.197988

Robinson CR, Sligar SG (1994) Hydrostatic pressure reverses osmotic pressure effects on the specificity of EcoRI-DNA interactions. Biochemistry 33:3787-3793 doi: 10.1021/bi00179a001

Robinson CR, Sligar SG (1995) Hydrostatic and osmotic pressure as tools to study macromolecular recognition. Methods Enzymol 259:395-427 doi: 10.1016/0076-6879(95)59054-4

Sambrook J, Fritsch E, F, Maniatis T (1989) Bacterial media, anitibiotics and bacterial strains. In: C N (ed) Molecular cloning. A laboratory manual. Second Edition. Cold Spring Harbor Laboratory Press, Cold Spring Harbor, pp A1-A13

Sarma R, Paul S (2013) Crucial importance of water structure modification on trimethylamine $\mathrm{N}$-oxide counteracting effect at high pressure. J Phys Chem B 117:677-689 doi: 10.1021/jp311102v

Saum SH, Müller V (2007) Salinity-dependent switching of osmolyte strategies in a moderately halophilic bacterium: glutamate induces proline biosynthesis in Halobacillus halophilus. J Bacteriol 189:6968-6975 doi: 10.1128/JB.00775-07

Scoma A, Barbato M, Borin S, Daffonchio D, Boon N (2016) An impaired metabolic response to hydrostatic pressure explains Alcanivorax borkumensis recorded distribution in the deep marine water column. Sci Rep 6:31316 doi: 10.1038/srep31316

Tian W, Chen C, Lei X, Zhao J, Liang J (2018) CASTp 3.0: computed atlas of surface topography of proteins. Nucleic Acids Res 46:W363-W367 doi: 10.1093/nar/gky473

Valette O, Tran TTT, Cavazza C, Caudeville E, Brasseur G, Dolla A, Talla E, Pieulle L (2017) Biochemical function, molecular structure and evolution of an atypical thioredoxin reductase from Desulfovibrio vulgaris. Front Microbiol 8:1855 doi: 10.3389/fmicb.2017.01855

Waterhouse A, Bertoni M, Bienert S, Studer G, Tauriello G, Gumienny R, Heer FT, de Beer TAP, Rempfer C, Bordoli L, Lepore R, Schwede T (2018) SWISS-MODEL: homology modelling of protein structures and complexes. Nucleic Acids Res 46:W296-W303 doi: 10.1093/nar/gky427

Xie Z, Jian H, Jin Z, Xiao X (2018) Enhancing the Adaptability of the deep-sea bacterium Shewanella piezotolerans WP3 to high pressure and low temperature by experimental evolution under H2O2 stress. Appl Environl Microbiol 84:e02342-17 doi: 10.1128/AEM.02342-17

Yancey PH, Siebenaller JF (2015) Co-evolution of proteins and solutions: protein adaptation versus cytoprotective micromolecules and their roles in marine organisms. J Exp Biol 218:1880-1896 doi: 10.1242/jeb.114355 


\section{Figure Captions:}

Fig. 1 Sequence alignment of a) the thioredoxin from D. piezophilus C1TLV30 (DpTrx1) and D. vulgaris Hildenborough (DvTrx1) (active site motif and residues important in the catalytic reaction are highlighted in gray) and $\mathrm{b}$ ) the thioredoxin reductase from $D$. piezophilus C1TLV30 (DpTR1) and D. vulgaris Hildenborough (DvTR1) (conserved motifs for thioredoxin binding (Trx1 bind.), active site (Active site), pyrophosphate group of NAD(P)H binding (PP binding) and phosphate group of NADPH binding ( $2^{\prime} P$ binding) are highlighted in gray). The alignments were generated using the ClustalW program from the IBPC server (npsa-prabi.ibcp.fr). Identical $(*)$, strongly similar (:) and weakly similar (.) residues are indicated.

Fig. 2 Enzymatic activity assays at 0.1 and $25 \mathrm{MPa}$ in the absence (white) or presence (gray) of glutamate. a) TR1/Trx1 complex from $D$. piezophilus C1TLV30; b) TR1/Trx1 from $D$. vulgaris Hildenborough. Mean values and error bars were obtained from at least 3 independent experiments. Significant differences between samples are indicated by an asterisk (Student's t-test, $p$-value $<0.01$ )

Fig. 3 Initial velocity under steady-state conditions for DTNB hydrolysis by the TR1/Trx1 complex of $D$. vulgaris Hildenborough at various glutamate concentrations

Fig. 4 a) NMR Lower energy structure of oxidized DvTrx1 (active site WCPGC in ball and stick colored in gray, S $\gamma$ atoms in orange). b) Cartoon model of oxidized DpTrx1 (active site WCPGC in ball and stick colored in gray, S $\gamma$ atoms in orange); additional acidic functions compared to DvTrx1 are represented by red spheres. c) and d) Surface charges of DvTrx1 and DpTrx1, respectively. e) Superposition of DvTrx1 and DpTrx1 with their corresponding dipolar moments; angle variation is indicated 
DPTR1 DVTR1

DPTR1

DVTR1

DPTR1

DvTR1

DpTR1

DvTR1

$$
10
$$$$
20
$$$$
30
$$

40

50

60

MAHQITDGTFDQEVLQSEIPVLIDFWAPWCGPCRAMGPVI DELSEEYADQVKIVKMNVDE MAAQITDATFEASVLKSA I PVLIDFWAPWCGPCRAMGPVI DELAAEYEGKVLIVKMNVDD

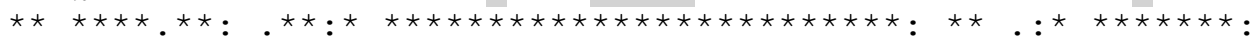

70

80

90

100

NSATPGKYGIRAIPTLILFKDGEVVDQSTGAVSKSSIKEMITKKALNPATPSKYGIRAIPTLILFKNGEVVEQVTGAVSKSS IKDMIAQKALG

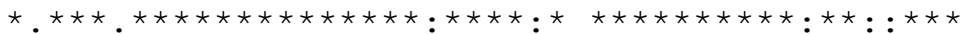

$\begin{array}{lllll}10 & 20 & 30 & 40 & 50\end{array}$

DPTR1 MKSYDAVVIGGGPAGMTAALYLLRAGVKTAMIEKLAPGGQVLMTAEIENYPGFPEGLQGW MQQFDAIVIGGGPAGMTAALYLARSGVSVAMVERLS PGGQVLMTSEIENYPGFPKGIQGW

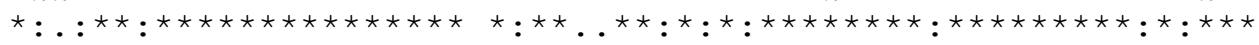

80

90

100

110

120

ELADKFAAHIENDELDR INDEVRS IELGTSLHT IHVGEQVVQTKMI I LATGSRYRKLGIP ELADLFAAHLEGYAITRFNDEVREIVPAPADNRVRVGDDWISGRTLILCSGARYKRLGLP

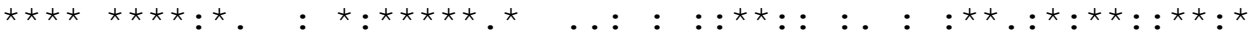

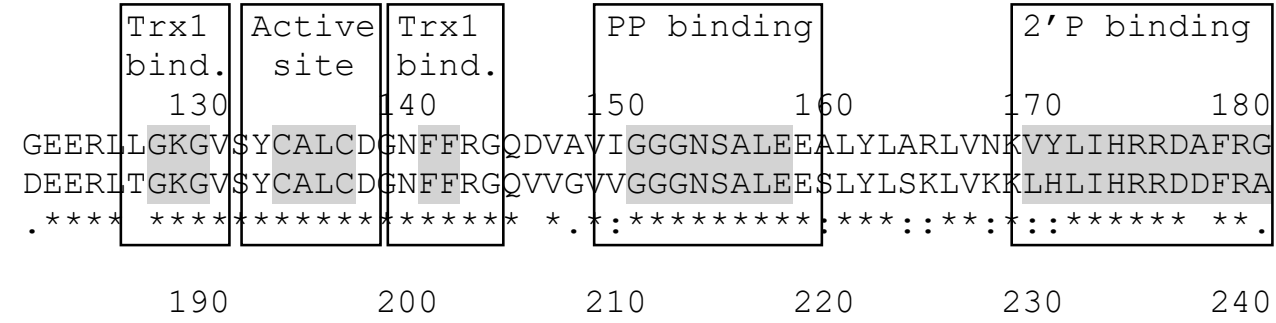

LLCYQDKCLNHEKIEVVRNTVVNEIEGADEVESLALCNVKSKESSHLKIDAAFVFVGFEP AKCYQDKVCIMPDIDVVRSSVVEAIHGDDRLTGVTVRNVKTGETSFLELDGLFIFIGFEP

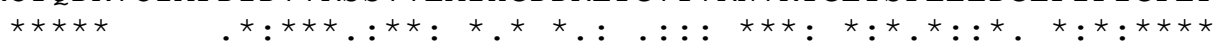

$250 \quad 260 \quad 270 \quad 280 \quad 300$

DPTR1 IMDFVPVEVERDKNG-IITDVEMRTNIPGVFAAGDIRSKLCRQVASAVGDGATAANAAFT DVTR1 VGGFLPGGIERDEQGFVITDGEMRTNLPGIFAAGDIRSKMCRQVTTAVGDGATAANAAFV

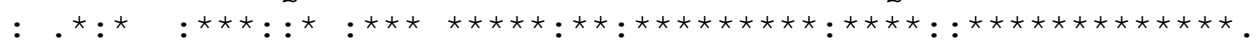


$463 \quad$ Fig 2

464

465

466

b
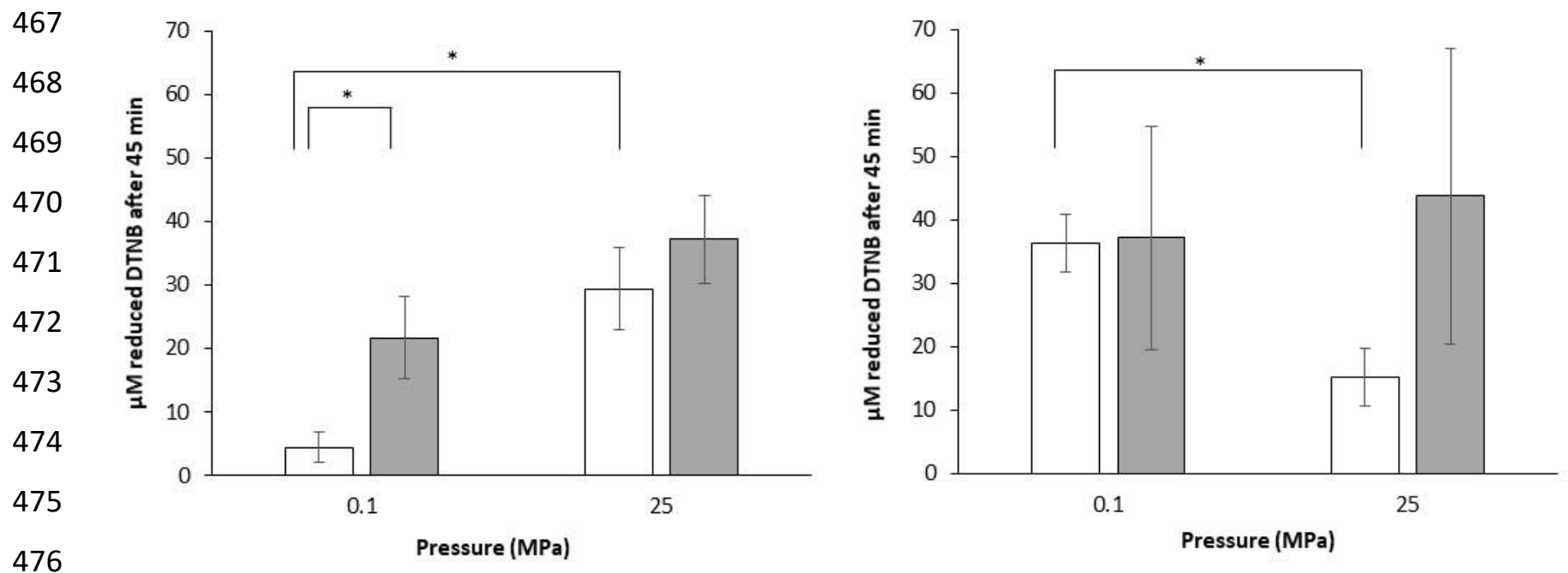

477

478 
479

480

Fig 3

481

482

483

484

485

486

487

488

489

490

491

492

493

494

495

496

497
I

$\Phi$

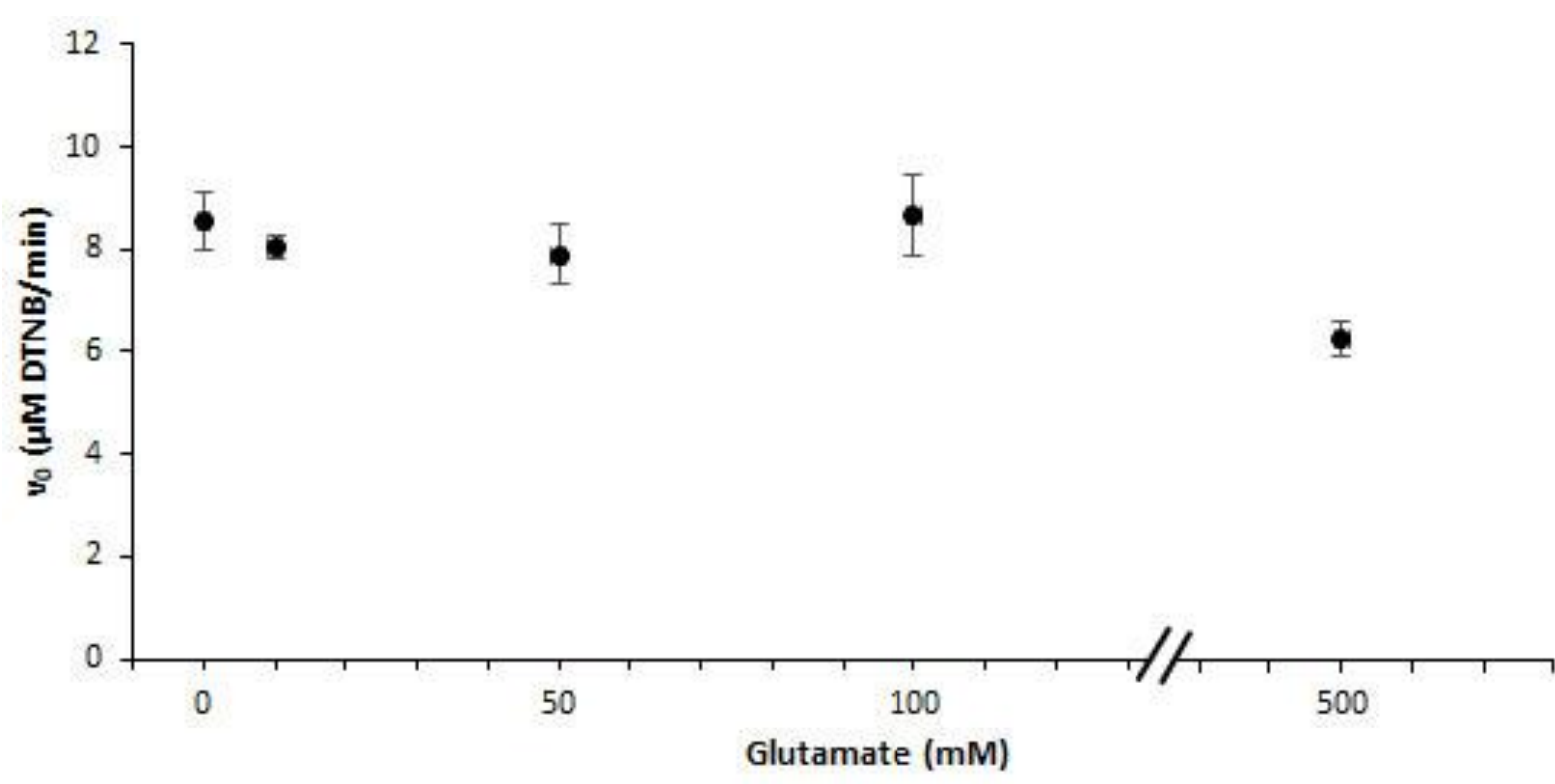


Fig 4

499

502

503

504

505

506

507

508

a

501

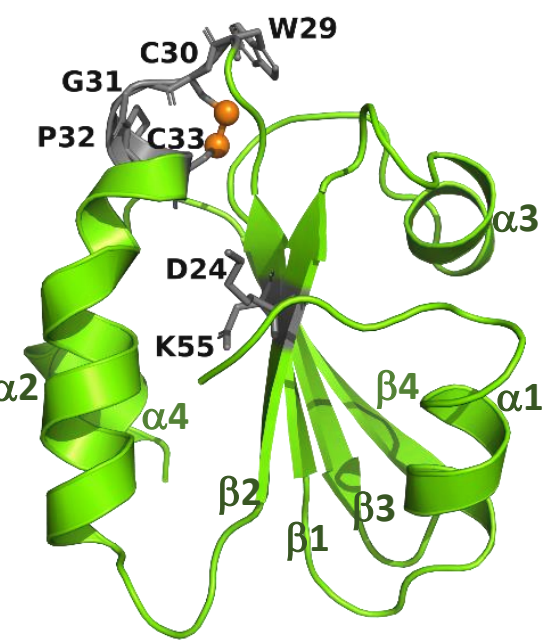

C

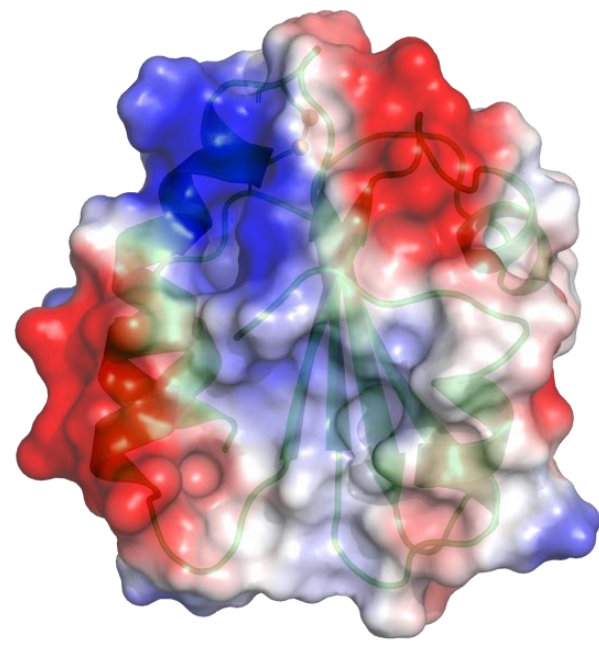

DpTrx1

e

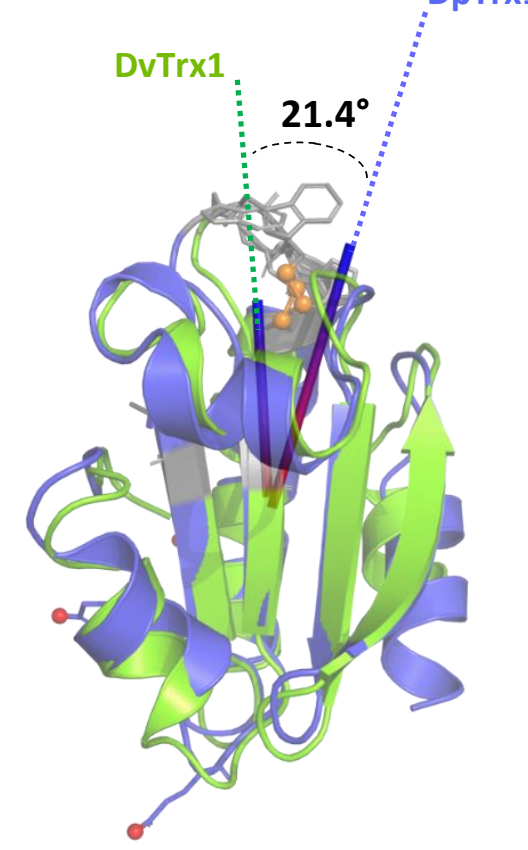

b

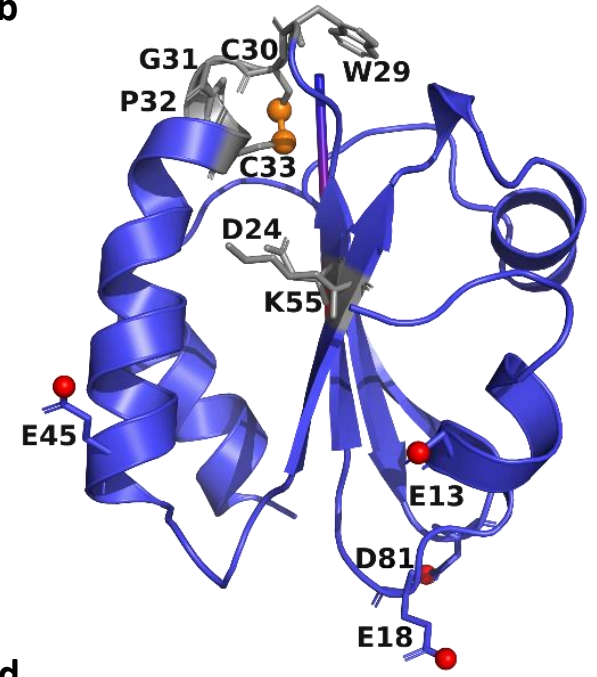

d

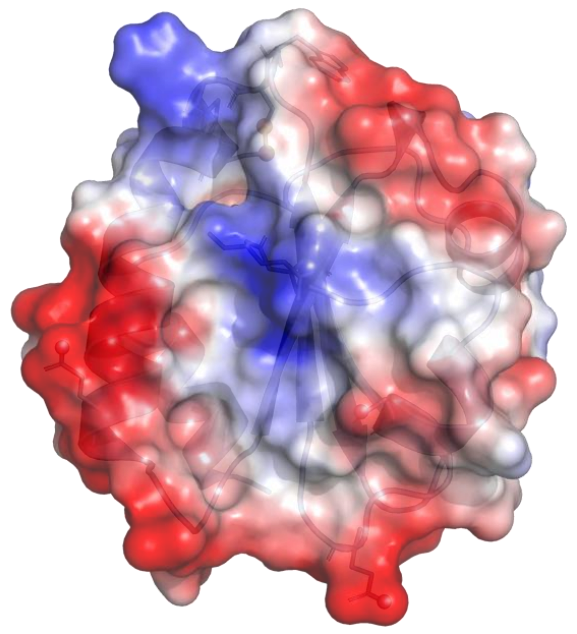


510 TABLE 1: Oligonucleotide primers DNA sequence used for specific amplification and cloning of the $D$.

511 piezophilus C1TLV30 TR1/Trx1system coding sequences.

\begin{tabular}{|l|l|c|}
\hline Name & Sequence 5'-3' & $\begin{array}{c}\text { Restriction } \\
\text { enzyme }\end{array}$ \\
\hline $\begin{array}{l}\text { trx1-10319- } \\
\text { fwHis }\end{array}$ & GGGAATTCATGCACCACCACCACCACCACGCACATCAGATTACGGAC & EcoRI \\
\hline $\begin{array}{l}\text { trx1-10319- } \\
\text { rev }\end{array}$ & TTGGATCCCTACAGCGCCTTCTTGGT & Bam HI \\
\hline $\begin{array}{l}\text { trB-10320- } \\
\text { fwHis }\end{array}$ & TTGAATTCATGCACCACCACCACCACCACAAATCATATGACGCTGTA & EcoRI \\
\hline trB-10320-rev & TTGGATCCCTAAATACCGAACTGTTGG & BamHI \\
\hline p119 + & GTTCTGGCAAATATTCTGAAATG & \\
\hline P119 - & GCTTCTGCGTTCTGATTTAAT & \\
\hline
\end{tabular}

512 The restriction enzyme recognition site is underlined in the sequence, and the six triplets encoding His-tagged

513 domain for convenient purification are shown in boldface. 
